\title{
Economic crisis and participation in Adult Education: \\ A qualitative investigation with primary teachers in Greece
}

\author{
Maria Papalexopoulou, Vassiliki Rorou, Thanassis Karalis \\ Department of Educational Sciences and Early Childhood Education \\ University of Patras, Greece
}

\begin{abstract}
In this research, a quantitative approach (semi-structured interviews) is used to investigate the views of primary education teachers, concerning their participation in continuing education programs. The investigation of the motives and barriers to their participation is based on the Morstain \& Smart and Cross typologies, while the present research's findings are compared to those of a quantitative research in Greece. As it turns out from the findings of the research, the recent severe economic crisis largely restrains the primary education teachers' options for participation in continuing education and lifelong learning.
\end{abstract}

\section{Indexing terms/Keywords}

Participation in adult education, motives and barriers to learning, lifelong learning, continuing education.

\section{Academic Discipline And Sub-Disciplines}

Adult Education, Lifelong Learning

\section{SUBJECT CLASSIFICATION}

Participation in Adult Education

\section{TYPE (METHOD/APPROACH)}

Qualitative approach (semi-structured interviews)

\section{Council for Innovative Research}

Peer Review Research Publishing System

\author{
Journal of Social Science and Research
}

\author{
Vol 3, No.1 \\ editor@cirworld.com \\ www.cirworld.com, member.cirworld.com
}




\section{INTRODUCTION}

Adult education is a field of educational activities that is radically different from the formal education of the school system and it essentially recommends a different approach and philosophy from the education of children in the context of compulsory studies. Thus, adult learners, in contrast to underage learners, are lead to the education process and adult education programs with specific goals and expectations, motivated by tangible needs that stem from particular problems and situations related to private and social life.

During the last three years Greek citizens experience the consequences of a very serious social and economic crisis that affects almost all fields of personal and professional activity. This crisis has resulted in the highest unemployment rate in contemporary Greece (almost 27\%) and a significant decrease of GDP by $25 \%$. Social benefits and salaries have been reduced dramatically, while at the same time primary and secondary education state funding has been cut down.

In this present research based on a qualitative approach, the participants were primary education teachers. The objective of the research was the investigation of the motives and barriers to the participation of the research's subjects in educational activities, under the circumstances of the economic crisis.

\section{MOTIVES AND BARRIERS TO ADULT LEARNING}

The first widely known systematic investigation of the reasons for participation in organized educational activities is attributed to C. O. Houle, who in the beginning of the 1960's investigated the adult learners' reasons for participation based on a qualitative approach (in depth interviews), among 22 learners that participated in various types of adult education programs. Houle (1961), through his theory, claimed that the participants in adult education are orientated either towards the goal, or towards the activity, or towards learning. Thus, Houle (1961) suggested a typology of adult learners, but in relation to the way they are orientated towards learning and not in relation to factors or motives to their participation, distinguishing three types: the goal-orientated, the activity-orientated and the learning-orientated.

Goal-orientated adult learners are supposed to be using education as a means to clearly defined ends. The activityorientated adult learners are the ones that participate because they find meaning in the education process and not in the development of a skill that does not necessarily relate to the activity's subject matter or goals. Those adults usually participate in order to escape loneliness and make new acquaintances or to get away from an unpleasant situation in their private or professional life. Finally, the learning-orientated ones seek learning for the joy of learning, usually as a continuing and lifelong activity. It seems that the quest for learning is both a way and a goal of life for them (Houle 1961; Cross 1981).

Starting from Houle's (1961) typology, Boshier (1971) created the Educational Participation Scale, emphasizing on the participation motives that are developed based on their orientations (Boshier, 1971; Boshier, 1973; Boshier \& Collins, $1985)$ and not only in the learner types. Consequently, Morstain \& Smart $(1974,1977)$ proceeded into the analysis of factors in the Educational Participation Scale and created their own Adult Participation Factor Scale in continuing education programs. They grouped the data in six categories - complexes of reasons for participation: Social Relationships (SR), External Expectations (EE), Social Welfare (SW), Professional Advancement (PA), Escape/Stimulation (ES) and Cognitive Interest (CI).

The factors that Morstain \& Smart highlighted correspond to the three adult learner groups of Houle. The "Professional Advancement" and "External Expectations" factors seem to present common elements with the group that Houle (1961) named "Learning-orientated adult learners". The goal of Professional Advancement can be set by a person aiming towards self-improvement, is generally motivated internally and has inner desires and needs. The reasons that motivate an adult to receive training on his profession may be connected to the ensuring of professional advancement, the ensuring of a higher status, the coping with the fierce and ongoing competition and the ever-growing conflicting interests. That, of course, does not entail that said person has a strictly instrumental relationship with education.

However, even in the instance that a person takes into consideration the expectations that others have towards him (External Expectations), she/he can set goals that on this occasion have been recommended by others or relate to the fulfillment of the expectations of a person with power, i.e an employer, who demands further learning related to the work, as well as understanding and adapting to the ever-increasing changes and continuing developments (Cross, 1981: 1987).

Particularly, if we wish to connect this concept to the one of social classes, we could note that Rogers (2002) claims that adult participation in continuing education programs is influenced by social surroundings and also that social class will affect, if not signify, the way that approaches learning. "In certain cases it will also determine whether he participates or not. Thus, it was observed that adult education concerns in a larger scale the middle class and those that have acquired a good education" (Rogers J., 2001).

The "Escape/Stimulation" and "Social Relationships" factors, as factors for participation in education, seem to satisfy "activity-orientated" people. People that participate in the activity and are orientated towards the activity itself, possibly seek to escape from boring, uninteresting, or even unpleasant situations. They try to feel relief and satisfaction, averting 
the tediousness and ennui of home, or even the disappointment that daily life's unpleasant situations cause. Simultaneously, they seek and need the forming of interpersonal and friendly relationships, the satisfaction of personal contact and the meeting of other people, something that motivates adult learners, gives them strength and acts encouragingly, helping them continue their learning course. They rely on lifelong learning, because, as a concept that is more and more important and is winning ground amidst the uncertainty of social and cultural change, it can help people find their place in society and look for a more human and more pleasant daily life. Many times, even if the real reason behind their participation is the escape from a tiring and tedious reality, they don't admit that it is indeed the real reason. They invent other reasons, clearly defined problems, as the acquiring of skills or general knowledge on a learning object, in order to conceal the true cause that lead them to learning. Concluding the similarities of adult learner participation factors in education, the "Cognitive Interest" factor seems to approach Houle's "learning orientated" adult. This implies that the adult learns "how to learn", seeks new knowledge, is interested in satisfying his curiosity and is satisfied with the fulfillment of his expectations.

We could say that that the "Social Welfare" factor matches the type of adult that is "activity-orientated". This concept is developed in the adult person as a need to contribute to society, to increase his skills in order to participate in community work, or even to prepare for participation in common affairs and generally as a need for qualitative improvement in his/her life as a whole.

Concerning the barriers in adult learning, it is true that everyone, regardless of age, when in a learning process, faces difficulties that hinder this process. Particularly, it is common that a person will encounter barriers that don't allow him to learn, to master new knowledge, acquire a new skill or adopt new values, views and behavior. Every person, according to the way he has been shaped, presents a relative learning disability, that is to say he can't learn certain things, has certain obstacles, certain learning barriers (Rogers, A., 2002).

Patricia K. Cross dealt thoroughly with barriers to learning. Cross (1981) had also suggested the now classic typology of barriers to participation in adult training programs, sorting the barriers in three groups: the situational ones, the organizational ones and the dispositional ones.

The situational barriers are those that describe the situation that the adult is in on a particular moment and include factors such as the lack of money or time, children's care for parents or the difficulty of going to where the lessons take place. The organizational barriers stem from the educational institutions' characteristics, and it is usually those very methods and procedures that discourage people from participating in such activities, for instance: the accessibility, readability and attractiveness of the learning subject, tuition fees, the days and hours of class and the lack of information on continuing education programs. The dispositional barriers are the psychological characteristics, namely the stance and the selfperception of a person elf as a trainee, such as self-esteem, participation in the group and age.

\section{METHODOLOGICAL ISSUES}

The goal of this research is to investigate the motives and barriers of primary education teachers, concerning their participation in adult education programs. In particular, we will investigate those factors that act encouragingly and motivate the teachers to participate in the education process and activity, as well as those that inhibit and obstruct the participation of adults in educational activities.

The subjects of this research were 25 primary education teachers. The research was based on a qualitative approach, since interviews, particularly semi-structured interviews were used as an instrument of recording data.

The research questions were the following:

1. What are the reasons and the motives for participation of adults in the continuing education programs?

2. Which are the barriers to adults' participation in continuing education programs?

We consider it important to report that the results of the first quantitative research in Greece that simultaneously regarded the participation rates, the barriers and the motives were published during the research period (Karalis, 2013). This particular research was carried out with a questionnaire among a representative sample of 1.200 citizens, chosen from the general population on behalf of the Labor Institute of Trade Union Confederation and the Small Enterprises Institute of General Confederation of Professionals, Craftsmen and Merchants of Greece.

Wherever possible, we will compare the findings of the present research (qualitative research on teachers) with those of the aforementioned research (quantitative research on general population).

\section{PRESENTATION OF FINDINGS - DISCUSSION}

The reasons why the subjects participate in continuing education programs, regard many aspects of life in general and daily life in particular. To begin with, the majority of the subjects report the fulfillment of professional goals as a reason for 
their participation (19 out of 25). They characteristically report that they need to be aware of matters relative to their profession, such as new books, new analytical programs, methods of teaching and educational techniques. Simultaneously, among their reasons for participation, we can discern specific motives that were mentioned in the previous units, such as the desire for constant alertness, the need and desire to learn and participate in the education process and cognitive interest. They desire, as they themselves claim, to be active citizens, to take continuous action in the field of education, to learn constantly and to learn new things so that they will always progress (19 out of 25). Another reason is the seminar's subject.

Concerning the motives of the subjects, the majority of teachers (23 out of 25 ) reports work efficiency and effectiveness as the strongest motive for participation. They claim that this particular motive is important because scientific knowledge is constantly progressing and employees need to be constantly informed on these developments. Furthermore, the research's subjects' work is such that it concerns people, the majority of whom addresses children and that is why they regard that it is their duty to know lots of things, to acquire knowledge, be more efficient in their subject and to be able to give through their contact, especially with children, everything in as much quality as possible. However, it is noteworthy that the sufficiency and the usefulness of the knowledge is an important factor for their performance in their work.

What's more, a large number of the subjects (20 out of 25 ) stated that they want to participate in those programs with the learning of new things as a motive. They claim that constantly learning new things, renewing and enriching their knowledge as well as training continually, is an inner need and desire of theirs. To conclude, the acquisition of new knowledge will practically help their teaching, as well as both their individual and professional improvement. A smaller number of participants (18 out of 25) claimed that they participate in adult education programs with active citizenship as a motive. They frequently and in numerous occasions connect the concept of the well-rounded citizen to the one of the wellrounded human. Particularly, they connect the concept of the well-rounded citizen to the capacity to understand social events and political phenomena, as well as to their active participation in the social and political proceedings. Furthermore, they view that the concept of the well-rounded human refers to elements of the self and the personality. They also claim that fulfillment and ascent to the level of the well-rounded citizen occurs after a certain amount of time, through multiple participations in education, through a general alertness and the effort that he puts into his/her education.

We note that in the quantitative research mentioned (Karalis, 2013), the motives presented as the most important are work performance $(24,3 \%)$, retention or improvement of work position $(19,3 \%)$ and the interest in the learning of new things $(17,2 \%)$. Both this research's findings and those of the present research taken into consideration, we conclude that the teachers view participation in continuing education programs as one of the basic factors of professional development.

Furthermore, concerning the difficulties faced by the subjects in the learning process, the cost of participation in the education programs proves to be the biggest barrier to adult learners. There is, among most of the subjects, worry and problems concerning the economic factor, even the difficulty of response and participation in educational activities. As they claimed, in the past the uncertainty of the economic factor didn't exist, wages were normal and adults had the capability of participating in education, even if payment was necessary. The number of subjects claiming that they find cost as a barrier to their participation is 15 out of 25 subjects. In the counterpart research by Karalis (2013) the cost of participation in education programs is the first barrier by prioritization (46,9\%) when the subjects are asked to pinpoint just one barrier, while it is encountered in $81,4 \%$ of the sample when the subjects have the option of pinpointing more than one barriers.

The distance from the place where the program is carried out is another important barrier to adult learners. Remote access and moving to the place where the program is carried out weren't barriers to the subjects in the previous years. Many of them stress that in the present moment in time and under these economic circumstances, they are unable to participate in an education program that is being carried out in another place. Nine (9) out of twenty-five (25) subjects view moving to the place where the program is carried out as a barrier to their participation, since they include the transportation expenses, the expenses of a possible stay in the place and the cost of participation in the program, while they claim that there are not enough programs carried out near them anymore.

Another barrier that obstructs the course of adult learning is the days and hours when the continuing education programs are carried out. Many subjects stated that during the days and hours that they cannot attend the programs, they have to meet other daily life obligations and occupations. However, apart from the difficulty they face with the various obligations and occupations of their daily lives, they also face difficulties with their works' shifts. Furthermore, many subjects state that it is not easy to regulate the hours and days the program will be carried out, whether it be them or the people in charge, namely the program organizers that do it. This happens because the program is specific and unalterable, since it is shaped based on certain criteria that facilitate the participation of some, while obstructing the participation of others. As a facilitation solution, they suggest the carrying out of seminars and continuing education programs during the weekends, during the holidays when they do not work, as well as during the summer, when it is much easier for them to organize their time. Seven (7) out of twenty-five (25) subjects view the days and hours that the programs are carried out as a barrier to their participation. In the quantitative research's results (Karalis, 2013), this barrier is in the 7th place $(3,2 \%)$.

The absence or lack of time is another barrier to adult learners. The subjects with limited time are either the ones that are parents and in extent have familial obligations, as well as obligations to their children, or those that have their time restrained by professional/workplace obligations. The number of subjects that regards the lack of time as a barrier to their participation is 5 out of 25 subjects. Consequently, the lack of time due to obligations possesses 4th place among teachers, while in the general population (Karalis, 2013), it possesses 2 nd place (20,4\%). Even though in these cases the 
alternatives of distance learning and e-learning are suggested, we note that even there the problem of time persists, but in a different form, such as the time required to study the material given or the attendance at the e-learning session (Karalis \& Koutsonikos, 2003).

\section{CONCLUSIONS}

In this research, we aim to investigate the motives and the barriers to primary education teachers concerning the matter of attendance of seminars or continuing education programs in their field. More analytically, we studied the motives and the reasons of participation for teachers in the learning process, as well as how they themselves perceive the motives in lifelong learning. Furthermore, we investigated the reasons that obstruct and discourage teachers to participate in the learning process, as well as how the teachers perceive those barriers in lifelong learning.

According to the results, the reasons for participation of a large number of teachers in continuing education programs is enrichment/acquisition of knowledge and skills, as well as education - continuous learning. Then, many of them present as a reason the subject of the seminar. The results concerning the motives showed that the majority of teachers designates efficiency and effectiveness in work as the most important motive for participation in adult learning. Particularly, the subjects stated that they desire to participate in adult learning with the learning of new things and the acquisition of new knowledge as a motive. Consequently, fewer of them attend a continuing education seminar or program in order to become well-rounded citizens. The subjects frequently and in many occasions connect the concept of the well-rounded citizen to the concept of the well-rounded human.

Concerning the reasons that obstruct teachers from participating in continuing education seminars or programs, the primary one appears to be the cost. The place and time parameters of the carrying out of seminars appear to be hindrances for teachers, while, finally, time seems to act as an inhibitory factor for many teachers.

Even though in the past there had only been a few relative researches on this specific subject in Greece, so that we are in a position to carry out reliable comparisons, from the findings of this research we conclude that the basic motives are included in the professional advancement (PA) category of Morstain \& Smart, while most of the barriers are included in Cross category of situational barriers. Under the present economic crisis the factors that are directly (participation cost) or indirectly (difficulty of transportation for attendance of programs) connected to the consequences of the research subjects' income reduction appear to constitute the basic complex of deterring factors and contribute to the decline in participation.

As for the primary education teachers that participated in the research, during the present period of severe economic crisis, the main barrier to participation is the cost of participation, while the most important motive is efficiency and effectiveness during their work. We note that these findings are largely in accordance with the findings of a related quantitative research among the general populace that was carried out around the same time in Greece.

\section{REFERENCES}

[1] Boshier, R. (1971). Motivational orientations of adult education participants: A factor analytic exploration of Houle's typology. Adult Education Quarterly, 21, 3-26.

[2] Boshier, R. (1973). Educational Participation and Dropout: a Theoretical Model, Adult Education Quarterly, 23/4, pp. 255-282.

[3] Boshier R. W. \& Collins J. B. (1985) The Houle typology after twenty-years: A large scale empirical test, Adult Education Quarterly, 35 (3), pp. 113-130.

[4] Boshier, R., (1989). "Participant Motivation" Lifelong Education for Adults: An International Handbook. Oxford: Pergamon Press.

[5] Cross, P., K. (1981). Adults as learners: increasing participation and facilitating learning. San Francisco: Jossey-Bass.

[6] Houle, C. O. (1961), The inquiring mind, The University of Wisconsin Press.

[7] Houle, C.O. (1960) «The education of adult educational leaders», бто Handbook of Adult Education in the United States, عпाн. M. Knowles, Adult Education Convention of the USA, Washington, DC. 
[8] Karalis, T. (2013) Motivation and Barriers to the Participation of Adults in Lifelong Education (Athens: Labour Institute of Trade Union Confederation and the Small Enterprises Institute of General Confederation of Professionals, Craftsmen and Merchants of Greece).

[9] Karalis, T., Sotiropoulos, L., \& Kampeza, M. (2007). La contribution de l'éducation tout au long de la vie et de l'anthropologie dans la préparation professionnelle des enseignants : réflexions théoriques, Skholê, hors série 1, 149-155.

[10] Karalis, T., \& Koutsonikos, G. (2003). Issues and Challenges in Organizing Web-based Courses for Adults, Themes in Education, 4/2, pp. 177-188.

[11] Morstain, B. R., \& Smart, J. C. (1977) A Motivational Typology of Adult Learners, The Journal of Higher Education, 48(6), 665-679.

[12] Morstain, B. R., \& Smart, J. C. (1974) Reasons for Participation in Adult Education Courses: A Multivariate Analysis of Group Differences, Adult Education, 22(2), 83-98.

[13] Rogers, J. (2001). Adults Learning. Buckingham: Open University Press.

[14] Rogers, A. (2002). Teaching Adults. Buckingham: Open University Press.

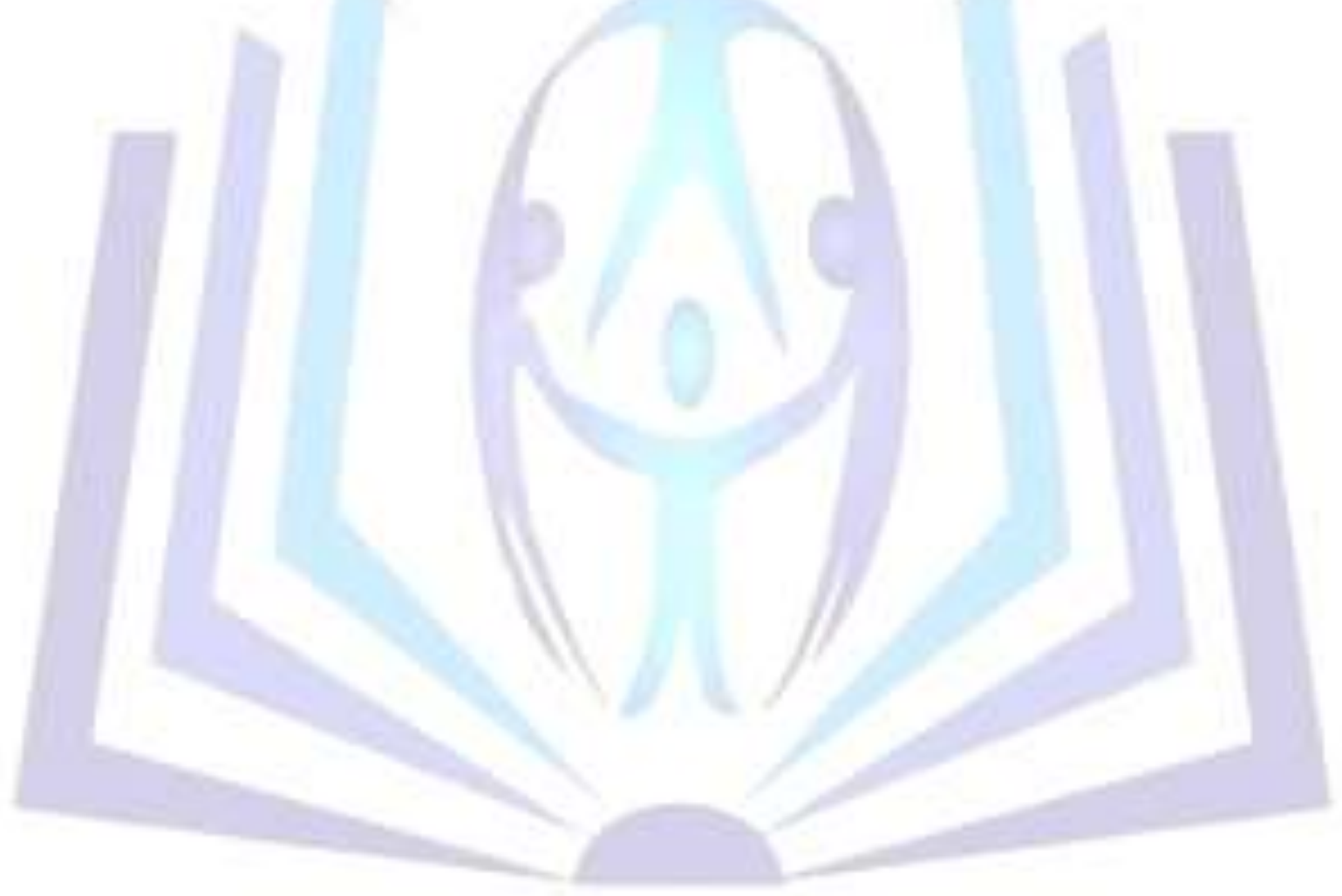

